\title{
EL FUTURO EN CUENTOS: DE OVNIS E IMPLANTES OCULARES EN LA CIENCIA FICCIÓN MEXICANA
}

\author{
POR \\ Héctor Fernández L'Hoeste \\ Georgia State University
}

La tradición de la cuentística de la ciencia ficción mexicana es muy longeva. Antologías como El futuro en llamas (1997) de Gabriel Trujillo Muñoz (1958), remontan el origen de una cuentística de ciencia ficción mexicana a fines del siglo XVIII, con historias como la del franciscano Manuel Antonio de Rivas ("Un viaje novohispano a la Luna"), siguiendo con relatos de autores más contemporáneos, como Amado Nervo ("La última guerra"), Julio Torri ("La conquista de la Luna"), Martín Luis Guzmán (“Cómo acabó la guerra en 1917”), Juan José Arreola ("Baby H.P.") y José Emilio Pacheco ("La catástrofe") (Trujillo Muñoz, El futuro). Dentro de este contexto, se entiende el que generaciones más cercanas hayan apostado a lidiar con el futuro en relaciones como "La pequeña guerra" (Premio Puebla de Cuento en Ciencia Ficción en 1984), de Mauricio José Schwarz (1955), o "Un hombre es un hombre", del mismo Trujillo Muñoz, ambas premonitorias de parábolas festejadas en el contexto de la cultura popular estadounidense (en el caso de Schwarz, un adelanto de la novela The Hunger Games [2008], de Suzanne Collins [1962] o de Battle Royale [1999], la obra de Koushun Takami [1969]; en el de Trujillo Muñoz, el del filme $W A L L \bullet E$ [2008], de Andrew Stanton [1965]). ${ }^{1}$ En este sentido, se sugiere una continuidad en relatos como "...Y el ovni cayó o el evento Ros. Huelitlán”, del versátil Francisco Gerardo Haghenbeck (1965, y quien también destaca por su apego a la historieta), y "Ruido gris", del esmerado Pepe Rojo (1968). En sendos cuentos reconozco, a la manera de los previos, un afán por anticipar el futuro y posibilitar una expansión de la mexicanidad más allá de las lindes sustentadas por el convencionalismo nacional azteca, afianzándose de manera tangencial

\footnotetext{
' Cabe anotar que, al igual que los libros de Collins, cuya adaptación cinematográfica se inició en 2012, Battle Royale cuenta con su correspondiente versión fílmica, dirigida por Kinji Fukasaku en el año 2000 y protagonizada, entre otros, por el magistral "Beat" Takeshi Kitano. Al igual que la norteamericana, con continuaciones en 2013, 2014 y 2015, la serie japonesa fue continuada en 2003 por el hijo del fallecido Fukasaku.
} 
en un contexto anglosajón. En México, teniendo a los EE.UU. tan cerca, lo clave radica en cómo imaginarse una modernidad sin que ésta se semeje demasiado a la de más al norte - sea canadiense o estadounidense-- Para ello toca apelar al amplio repertorio de mecanismos identitarios de la vivencia nacional -la geografía, la gastronomía, la lengua, los monopolios, los desmanes gubernamentales, la consabida desigualdad social, etc.- con el fin de postular versiones del futuro que permitan vislumbrar mundos alternos, otros Méxicos, que, sin dejar de ser México, son harto diferentes. En este sentido, esta nueva generación de fabulistas lo está logrando. Para Haghenbeck, la ciencia ficción facilita la oportunidad de festejar con humor la dureza e irracionalidad estatal, mientras que Rojo arremete contra la universalidad de los medios en la vida nacional - dos constantes ultramexicanas-. En ambos casos, aventuro, el formato de una trama condensada exacerba la crítica de lo nacional-popular y sugiere que, más allá del agotamiento del estado-nación como figura detentora de la potestad identitaria latinoamericana y del nacionalismo como discurso factible en materia de cuestionamiento político - para quienes arguyan acerca de espacios poshegemónicos-, el cuento de ciencia ficción se mantiene de forma indefectible como género propicio para el escrutinio cultural.

En los años cincuenta, en medio de su labor investigativa de los quehaceres del Santo Oficio en la Nueva España, el historiador mexicano Pablo González Casanova (1922) descubrió una causa abierta contra un fraile dominico llamado Manuel Antonio de Rivas, residente de Mérida, Yucatán, involucrado hacia el año 1773 en un proceso de herejía por parte del tribunal de la Santa Inquisición (Trujillo Muñoz, Biografias 27-31). Su pecado era simple: la escritura de una relación de larguísimo título: "Sizigias y cuadraturas lunares ajustadas al meridiano de Mérida en Yucatán por un anctítona o habitador de la Luna y dirigidas al bachiller don Ambrosio de Echeverría entonador que ha sido de kiries funerales en la parroquia de el Jesús de dicha ciudad y al presente profesor de logarítmica en el pueblo de Mames de la península de Yucatán; para el año del señor de 1775". (Es por ello que antologías contemporáneas de ciencia ficción favorecen un título más abreviado.) Empero, su crimen era más escueto: plasmando de manera bastante franca la influencia de los aires redentores de la Ilustración, el apoyar el método científico e imaginarse otras formas de gobierno ajenas a las planteadas por los monarcas peninsulares de la época. En la historia, hija del amor de fray Manuel por las matemáticas, la física y los clásicos grecolatinos -reflejando la próxima llegada de un espíritu libertario a tierras americanas-, un francés (que no un español) de nombre Onésimo Dutalón (natural de Baylliage d'Étampe, según la prosa) protagoniza un viaje espacial a la luna. De hecho, en voz del pedante Dutalón -así le describe Rivas-, la narración incluye juicios que pudieran ser juzgados como antimonárquicos. De manera tal que fray Manuel es perseguido, dadas las charlas de Dutalón con los anctítonas en la Luna, entre las cuales figura -aparte de un interés cabal por la comprensión del universo, bastante afianzado en el método científico- una cierta inquietud por la justicia 
y la equidad, pretensión deleznable para los amigos de la nobleza chapetona. Hacia esa fecha (1773), también, el fraile ya era un anciano, por lo que su narración ha de ser de fecha previa. Cuando González Casanova lo menciona en La literatura perseguida en la crisis de la colonia (1958), tilda el texto de "cuento fantástico". Lo cierto es que dicho relato inaugura la tradición cuentística de ciencia ficción en el país azteca. Sin embargo, hacia este punto, la continuidad se da de manera lenta. Cerca de cien años más tarde, el periodista Pedro Castera (1846-1906) habrá de publicar "Un viaje celeste", un cuento similar, en el que la aventura cósmica figura como excusa para toda suerte de disquisiciones, amalgamas de ciencia y mística, acerca del sistema solar y el espacio (Lockhart 50-51).

El impacto de la Revolución Industrial ayuda a que las cosas se muevan de forma un poco más rápida a partir del siglo XX. Al fin y al cabo, con inventos como la máquina de vapor y el automóvil, aunados al auge ferroviario, la vida se acelera. Hacia 1906, con el poeta Amado Nervo (1870-1919), se instaura una sucesión más contemporánea dentro de la tradición del cuento de ciencia ficción mexicana. En "La última guerra", muy en el espíritu turbulento de la época, Nervo nos ubica en un futuro en el que ya han acontecido tres grandes revoluciones -la cristiana, la francesa y la socialista-y sólo queda por darse la última: la de los animales, a la manera de The Planet of the Apes (El planeta de los simios, 1968), el filme basado en la novela homónima del francés Pierre Boulle. Aferrándose a pautas finiseculares, la de Nervo es una humanidad darwiniana, presa de dinámicas evolutivas, según las que la clase proletaria en algún momento ha contado con seis dedos en la mano derecha y a los conductores de múltiples clases de vehículos se les han atrofiado las piernas de tanto andar en vehículo. Así fuera socarronería, algo de ludismo había en Nervo. Presenciamos en la historia el discurso de Can Canis, líder de los animales, justo antes del momento de la rebelión, la cual se prolongará por espacio de diez años y será rememorada por el narrador, uno de los pocos humanos sobrevivientes. Años más tarde (1917), Julio Torri (1889-1970), quien da nombre a la librería del Centro Cultural Universitario de la UNAM, redacta un brevísimo texto en el que narra la conquista de la Luna -la obsesión mexicana por el tema, si bien se sugiere como piedra angular de la cuentística de CF, quizás también busque honrar una fijación amerindia-, a partir de la cual se pierde el hábito de escribir, descrito como "una imperfección" previa a la conquista del satélite. En otras palabras, los conquistados logran imponer preferencias sobre los conquistadores, eventualidad terriblemente diciente en el contexto de la historia mexicana. Ese mismo año, Martín Luis Guzmán (1887-1976), ofrece un anticipo del filme 2001: A Space Odyssey (2001: una odisea del espacio, 1968), del genial Stanley Kubrick (1928-1999) - a su vez basado en "The Sentinel” (El centinela), un cuento del británico Arthur C. Clarke (1917-2008)-, en el que una computadora de las Oficinas Centrales de la Censura del Departamento de Lenguas Romances, diseñada para identificar espías o subversivos, opta por tomarse 
el gobierno. Días antes del levantamiento, la máquina escupe una ficha delatora, la cual pone en alerta al narrador, quien, de manera infructuosa, se empecina en resolver el enigma y sobrevive al desastre (López Castro 76-77). En una era en la que aún no acecha la cibernética, el cuento sirve de anticipo nefasto al mundo de la informática. Pareciera que esto de adelantárseles a las letras y cinematografías europeas y norteamericanas, tan ostentosas de su modernidad, viniera de vieja data. En este sentido, valdría la pena meditar un poco acerca de la calidad de la condición de la modernidad en la nación azteca.

En 1932, el tapatío José Martínez Sotomayor (1895-1980) publica a contracorriente el cuento "Neocentauro", en el que, anticipándose al cyborg y quizás aventurando una variante de cíberpunk (o por lo menos steampunk) avant la lettre, describe la fusión de un humano, el académico de historia natural Enrique Pérez, y un automotor, engendrando un cuadrúpedo con cerebro indulgente. A ciencia cierta, el cyborg, habiendo pasado ya por las manos de Poe, La Hire y Hamilton, no era, a esas alturas, nada nuevo, pero de todas maneras llama fuertemente la atención en manos de un tapatío. Al igual que otros textos de la época, apremiados por una realidad que cambiaba de manera precipitada, el relato critica de forma acérrima el carácter deshumanizante de un mundo mecanizado (Lentitud). Hacia 1952, Juan José Arreola (1918-2001) publica “Baby H.P.”, historia en la que, parodiando el quehacer del mundo publicitario, fracción cosmética del capitalismo, describe un dispositivo de almacenamiento energético para niños -en otras palabras- un aparato que logra aprisionar la energía producto del berrinche y almacenarla para efectos de su uso en casa, reincidiendo en la geometría del revés - de los animales, de las máquinas, etc.--, tan ajustada a la realidad mexicana (Bell y MolinaGavilán, Cosmos Latinos 58-60). Para Arreola, la energía puede a veces ubicarse en los sitios más inesperados, a la manera de Soylent Green (1973), de Richard Fleischer (1916-2006), a su vez basada en Make Room! Make Room! (¡Abran campo! ¡Abran campo!, 1966), de Harry Harrison (1925-2012). Ya en tiempos más cercanos, en los que el impacto de la técnica es categórico, se da una genuina profusión de relatos. En 1984, el recientemente fallecido José Emilio Pacheco (1939-2014) publica "La catástrofe", un conciso cuento del volumen La sangre de Medusa, en el que se imagina una nación invadida por una potencia extranjera, gracias a la desidia y el malinchismo de los mexicanos, perennemente dispuestos a favorecer lo ajeno (según aventura el narrador). Citando la invasión estadounidense de 1847 y evocando de manera mordaz el mito de Juan Escutia, Pacheco pone armas ultrasónicas, capaces de segar "regimientos enteros" desde lejos, en manos de centinelas extranjeros (Schmelz). Si bien el cuento fustiga la ausencia de filiación anímica en algunos mexicanos, también se mofa de la mitología nacional-popular. Narrativas como éstas le miden el pulso al nacionalismo mexicano y, pese a cualquier evidencia de lo contrario, clarifican el vigor de su vigencia. Estos relatos, tan sólo algunos de los muchos que sugieren la continuidad del quehacer cuentístico de ciencia ficción mexicana, sientan una pauta, pues desde ya conjugan un sentimiento 
identitario alterno con la crítica futurista; esto es, pujan por expandir el sentido de la mexicanidad y abogan por la aceptación de nuevas formas. Es así como en los años ochenta, noventa y dos mil se cimienta una raigambre más firme, ya conocedora y más segura de su práctica.

Por ende, los relatos siguientes, los de Schwarz, Trujillo Muñoz, Haghenbeck y Rojo, son apenas unos cuantos de los muchos dedicados a consolidar una praxis que, a lo largo de varios siglos, se ha insinuado irreverente y redentora. En ellos, es factible reconocer la maduración de temas que se asoman de manera furtiva en los relatos de Rivas, Nervo o Arreola. Según he mencionado, "La pequeña guerra", el relato de Mauricio José Schwarz, ganó el primer Premio Puebla de Cuento de Ciencia Ficción en 1984, dando pie a la etapa contemporánea de la ciencia ficción mexicana, en la que aparecen premios que dan reconocimiento y estímulos a quienes laboran en este campo. Al mismo tiempo, dada la consonancia del título, plantea un nexo con el relato de Nervo. "La pequeña guerra", sin embargo, habla de otro tipo de pugna; narra la historia de la pequeña Arianne, quien es entrenada por sus padres, Akira y Guinnivere, para participar de manera mortífera en la competencia de lucha impuesta por el gobierno como parte de un sistema de control poblacional. A la edad de los diez años, todos los niños son obligados a luchar a muerte en un estadio, con el único aliciente de armas de defensa y ataque provistas por sus progenitores; el valor de las mismas no habrá de rebasar un veinte por ciento del patrimonio familiar. La medida, de tan sólo veinte años de antigüedad en el mundo del cuento, no cobijó a los padres (la madre se salvó por tres meses). El cuento narra tres enfrentamientos de Arianne. En los primeros dos, prevalece ante una chica más espigada y un muchacho de ojos profundos. En el tercero, Arianne sucumbe de forma súbita e inmisericorde, casi desprendida, ante una pequeña que, de manera habilidosa, esgrime una expresión suplicante y aprovecha el percance para aniquilar a su contrincante. La muerte de Arianne llega de manera certera e inesperada, sin adornos. La historia concluye con el inmediato inicio del entrenamiento de Jünge, hermano menor de Arianne, de tan sólo ocho años, y la insinuación del suicidio de Arianne, hastiada de vivir en una sociedad que la obliga a matar.

Según Schwarz, el cuento nació de su afán de comentar sobre la competitividad voraz que la nueva derecha impulsaba en los años ochenta mediante las políticas económicas del presidente estadounidense Ronald Reagan y la primera ministra británica Margaret Thatcher, quienes apoyaban una agenda interesada en ganar a como diera lugar, arremetiendo en contra de sindicatos de controladores de vuelo y mineros, privatizando sectores oficiales a diestra y siniestra con la aparente excusa de lograr mayor eficiencia -cosa que, a ciencia cierta, sólo se dio en algunos casos-. (En el contexto mexicano de la época, algunas de las políticas económicas del PRI -Partido Revolucionario Institucional-, y posteriormente las del PRD -Partido Revolucionario Democrático-, se ofrecieron como equivalencias improvisadas.) Para el autor, dicha 
orientación conducía de manera inexorable a una deshumanización, dado el imperativo de reemplazar el Estado - una empresa social con metas más amplias- con iniciativas privadas -con la maximización de la utilidad por único interés-. La idea de imponer medidas tan carentes de compasión con el objeto de lograr un orden social deseable, haciendo caso exiguo de implicaciones mayores, se le hacía indicativa del tipo de espíritu fomentado por ambos líderes archiconservadores. Desde esta perspectiva, considerando el prolongado brío del conservadurismo en el contexto anglosajón de los años posteriores, con el respectivo auge de movimientos como el Tea Party y el British National Party, no extraña la posterior coincidencia con la obra de Collins. De esta manera, desde una latitud azteca, Schwarz es una suerte de adelantado en su meditación crítica acerca del orden económico del ámbito anglosajón. De igual forma, a Schwarz le interesaba explorar las consecuencias de la intervención de los profesionales de la Iglesia en la vida civil y política. Cabe anotar que fue tan sólo en 1992 cuando las leyes mexicanas se adecuaron al derecho internacional en materia de libertad religiosa, de manera que las inquietudes de Schwarz son de entender. La libertad de cultos es añeja en México (data de 1860), pero se han visto desmanes de lado y lado (los cristeros, para citar un caso bien conocido). En la historia se menciona, por ejemplo, la violenta oposición de las iglesias a la medida (el espectáculo de una batalla campal a los diez años) pero no por razones humanitarias: al implementarse la medida, los primeros en caer son los hijos ilegítimos de los sacerdotes. Por último, a Schwarz le atraía ampliar el entendimiento de un proceso de mestizaje con nombres (Akira [Japón], Arianne [Francia], Guinnivere [Gran Bretaña], Jünge [variante asquenazí de un nombre germánico], Karl [alemán], etc.) sugerentes de una mezcla más allá de lo conocido en México. ${ }^{2}$ En otras palabras, a Schwarz le cautivaba lo pluricultural antes de su advenimiento noventero. En un país en el que el paradigma del mestizaje ha reinado virtualmente incuestionado desde los tiempos de Vasconcelos, fundamentado el mito de una democracia racial, llama la atención el interés de Schwarz por explorar otra forma de diferencia identitaria. Tal vez involucre un conato de cosmopolitismo. El centrarse en una onomástica delatadora de proyectos hegemónicos o imperiales-Japón Francia, Gran Bretaña y Alemania-también dice mucho de su ademán crítico. De manera adicional, el cuento está sin lugar a dudas influido por el acelerado crecimiento poblacional de la unión mexicana durante los años sesenta y setenta, con muy elevadas tasas de natalidad, cuando la capital nacional infundía una alarmante sensación de hacinamiento. ${ }^{3}$ No es de extrañar que semejante

2 Cabe notar la ausencia de nombres africanos, árabes, indios o polinesios. Al parecer, a Schwarz le interesaba matizar su narrativa con una onomástica de tradición imperial, bien familiarizada con la modernidad.

3 A este efecto, favor ver el informe de María Eulalia Mendoza García y Graciela Tapia Colocia sobre la situación demográfica mexicana de 1910 a 2010, disponible en el sitio web del Fondo de Población de las Naciones Unidas: <http://www.unfpa.org.mx/publicaciones.php>. 
aprehensión, aunada al sentimiento de omnipotencia atizado por el unipartidismo del siglo XX -según el cual el gobierno era capaz de todo tipo de excesos-, resulte en una historia al estilo de la de Schwarz. De esta manera, su corto relato se convierte en laboratorio de un nuevo tipo de identidad que, si bien no se declara mexicana-el cuento carece de mención específica-ha sido concebida y producida en un contexto nacional.

En el caso de "Un hombre es un hombre", de Gabriel Trujillo Muñoz, uno de los autores más prolíficos de la ciencia ficción mexicana, la historia narra la llegada de un hombre a un espacio regido por máquinas. De hecho, en la historia, redactada entre 1999 y 2001, una máquina apodada Simulacra hace las veces de narradora. Con años de sobra, el desfile de máquinas en la historia de Trujillo Muñoz se adelanta al mundo de $W A L L \bullet E$, el filme de Pixar: en el diálogo figuran una vieja recicladora de basura, un guardián exterior, un acumulador de alimentos, una captadora de transmisiones, un sensor ecológico, una enciclopedia gráfica ilustrada, un apostador de posibilidades, una holograficadora de realidad virtual y la narradora. El ardid de la historia consiste en que, al aparecer un hombre, éste se rehúsa a aceptar el consejo de Simulacra, quien se ofrece a acompañarle como guía en su viaje a través del desierto cercano, en donde, le previene, acechan grandes peligros, como aves de presa, espejismos y contaminación. Al marcharse el hombre, el cual supuestamente sucumbe al ataque de las aves -en el fondo, se escuchan disparos, gritos y graznidos de triunfo-, resulta que el sujeto ha sido producto de la holograficadora, quien se jacta de lo bien que le ha quedado. En ese momento, los lectores se enfrentan a una nueva realidad: las máquinas están decididamente solas y la humanidad ha desaparecido. Lo sorprendente radica en que, convirtiéndose en realidad, el hombre regresa malherido de su travesía por el desierto -en ese momento, en admisión del desliz, la holograficadora echa chispas- y fallece en brazos de Simulacra, quien, atónita, se resigna a su soledad en un mundo exento de seres humanos.

Trujillo Muñoz reconoce haberse inspirado en Ciudad (1952), del estadounidense Clifford Simak (1904-1988), una colección de historias que narra el colapso de la humanidad, comenzando por el abandono de las ciudades y un éxodo hacia el campo. A diferencia de otras parábolas apocalípticas, en Ciudad, el fin de la humanidad no llega por destrucción, sino por retraimiento. La humanidad comienza a aislarse $\mathrm{y}$, en medio de su soledad, desaparece. En el relato de Trujillo Muñoz, de manera irónica, los robots terminan siendo más humanos que los humanos mismos, ansiando la compañía de la vida orgánica, tan propensa al desastre según el autor. De hecho, la nostalgia de las máquinas se delinea como un rasgo aún más humano que el afán de soledad o aislamiento de quienes viven en una gran civilización. En el contexto mexicano, pudiera aventurarse que alguna de la responsabilidad le compete al renovado ímpetu privado -en materia 
económica y espacial- sustentado por una precaria modernidad latinoamericana. ${ }^{4}$ De igual manera, el estilo de la narración, fincado en diálogos escuetos y descripciones concisas, de índole fílmica, forma parte de un momento en el quehacer del escritor en el que la opacidad narrativa ha quedado atrás.

Ambos cuentos son bastante dicientes del papel de la modernidad en la realidad mexicana - o por lo menos de un cierto entendimiento de la misma condición-. El hecho de que un par de autores aztecas anticipen hasta cierto punto temáticas y aproximaciones a la modernidad que luego serán problematizadas por la industria cultural estadounidense es muy ilustrativo del grado de meditación mexicana en cuanto al carácter disparejo y periférico de su versión de modernidad. En el caso de "La pequeña guerra", llama la atención el afán por la pluralidad, dado el grado de homogeneización en la sociedad mexicana en torno a un paradigma de mestizaje. Si bien en México la diferencia ha estado marcada de manera mayoritaria por una asociación de clase, dada la fuerte discrepancia económica, llama forzosamente la atención el que la historia se preocupe por un mestizaje más amplio, más allá del señalado por el proceso histórico nacional, en el que los invasores europeos se mezclaron con amerindios y africanos. (Ahora bien, pese a los números de censos de la época colonial-los cuales certifican el no despreciable tamaño de una población afro descendiente en México-, el mulataje mexicano dista de ser materia aceptable de comentario, dado el grado de negación en la historia oficial) (Aguirre Beltrán). Al parecer, dentro del marco de la ciencia ficción mexicana, existe gran conciencia e interés por la vinculación del país a un marco más amplio, cosmopolita y rebasador de las limitaciones impuestas por el análisis histórico convencional. Quizás por esa razón el autor ha optado por favorecer una onomástica que, de cierta manera, rechaza la inclusión de nombres amerindios, tan comunes en el contexto diario mexicano, y de corte africano, dada la ausencia problemática de estos últimos en el mismo. En cambio, no llama tanto la atención el que la temática del cuento se haya centrado en torno a una medida draconiana fundamentada en el afán de lidiar de forma expedita con la sobrepoblación. Durante buena parte de la era moderna -con muy escasas excepciones: quizás el caso de Nueva York a fines del siglo XIX y a comienzos del XX-, Ciudad de México ha ostentado la poco estimable distinción de ser la zona metropolitana más poblada de las Américas, condición experimentada con mayor intensidad que en otras latitudes a raíz de su elevada densidad poblacional. De ahí que una historia con tintes de maltusianismo y trazos de dictadura - esta segunda faceta más fincada en la deficiente tradición democrática del monopartidismo oficialista durante la mayor parte del siglo $\mathrm{XX}$ - resulte por ventura más predecible en el contexto mexicano que estadounidense. En ocasiones, el espíritu crítico y el fatalismo se confunden.

4 Según el Banco Mundial, pese a tratarse de la segunda mayor economía latinoamericana, la tasa nacional de pobreza en México en 2012 fue del 52,3\%. A este efecto, favor ver la información disponible en $<$ http://data.worldbank.org/country/mexico $>$. 
Por otro lado, el caso de "Un hombre es un hombre" resulta más revelador, por tratarse de una temática que, a primera vista, dista de tener matices particularmente relevantes a la modernidad mexicana, tradicionalmente vista como relativamente ajena a la tecnología. Pero, ¿qué tan cierta resulta esta lectura? Crónicas recientes del desempeño técnico azteca resaltan el potencial del país para opacar incluso a la India en materia de tecnificación, convirtiéndose en efecto en el gran laboratorio de autómatas de las Américas. ${ }^{5}$ De hecho, según cifras vigentes, hay un mayor número de egresados de facultades de ingeniería en México que en Canadá, Alemania o Brasil. Dicho cubrimiento noticioso aclara que el déficit mexicano se plasma en materia de trabajo (a nivel profesional y obrero), que no en este particular campo de la educación - de ahí la escasa movilidad social-, pues el número de instituciones educativas con programas de preparación técnica y licenciatura se ha duplicado en los últimos diez años, atendiendo una demanda desabastecida por el tradicional sistema de educación pública.

Un repaso de ciertas disciplinas también sirve para rebatir un entendimiento viciado de la relación entre la mexicanidad y la tecnología. En el área de las comunicaciones, cabe recordar que un mexicano, el ingeniero Guillermo González Camarena (19171965), fue el inventor de la televisión a color, y que, en América Latina, la industria televisiva arrancó por México. Según los más recientes cálculos, el mercado mexicano de telecomunicaciones suma 20 millones de líneas fijas, 100 millones de teléfonos móviles y 50 millones de usuarios de Internet, cifras alcanzadas a lo largo de la última década, en la que se ha dado un salto exponencial en materia de telecomunicaciones. ${ }^{6}$ De igual forma, la impronta tecnológica mexicana es muy visible en otras naciones del hemisferio. América Móvil, propiedad del Grupo Carso, del archimillonario Carlos Slim Helú, cuenta con presencia en Argentina, Brasil, Chile, Colombia, Ecuador, EE.UU., Perú y Uruguay; maneja también el 70 por ciento de las líneas móviles mexicanas y 80 por ciento de las fijas. Televisa, su más cercana competidora en materia de acceso a Internet y TV por cable -con el 60 por ciento del mercado televisivo azteca-, es la mayor empresa de medios de comunicación del mundo hispanohablante. Y la envergadura tecnológica azteca no se ciñe tan sólo al área de los medios o telecomunicaciones. En materia de industria automotriz, por citar otro ejemplo, un rubro fuertemente impactado por la automatización y tecnificación de sus líneas de ensamblaje, México ocupa el octavo lugar del mundo (y el cuarto en materia de exportación, tan sólo por debajo de

\footnotetext{
5 A este respecto, favor ver el artículo de Vivek Wadhwa, "How Mexico Can Leapfrog India and Become America's Automaton Workshop", disponible en la version en línea de Forbes: http://www.forbes. com/sites/singularity/2012/11/19/how-mexico-can-leapfrog-india-and-become-americas-automatonworkshop/. O la nota de William Booth en The Washington Post sobre el creciente número de egresados de facultades de ingeniería en México: <http://www.washingtonpost.com/world/the_americas/mexicois-now-a-top-producer-of-engineers-but-where-are-jobs/2012/10/28/902db93a-1e47-11e2-881741b9a7aaabc7_story.html>.

6 Ver datos en: $<$ https://www.cia.gov/library/publications/the-world-factbook/geos/mx.html\#Comm>.
} 
Japón, Alemania y Corea del Sur), produciendo casi tres millones de unidades cada año, muy por encima de España, Francia o el Reino Unido -y dicha cifra va en aumento, gracias a nuevas plantas de marcas japonesas y alemanas-. ${ }^{7}$ Se estima que, al presente paso, México pronto eclipsará a Brasil como potencia automotriz latinoamericana y que ya se perfila como un pronto reemplazo de Japón como principal exportador automotor a los EE.UU. Dentro de esta misma materia, destacan sus bajos costos de operación (salarios bastante bajos en comparación con la media mundial de la industria automotriz), elevada productividad (el hecho de haber optimizado al máximo la eficiencia del operario mexicano, aprovechándose de su nivel de capacitación y a punta de una extendida automatización de líneas de ensamblaje), una mano de obra calificada (el elevado número de jóvenes desempleados, recién egresados de noveles facultades de ingeniería) y una buena relación entre la industria y la academia (una abundancia de pasantías y colaboraciones acomodaticias entre ambas). En semejante entorno, tan propenso a un espíritu empresarial depredador (tan propenso al exceso capitalista y al mono u oligopolio), al avance tecnológico y la industria pesada, no extraña el que un autor como Trujillo Muñoz alcance a imaginarse un futuro sombrío y producto de la enajenación, habitado de manera exclusiva por máquinas. Resulta que la relación entre la mexicanidad y la tecnología - dicho sea de paso, de una variedad altamente deshumanizante- es mucho más próxima de cuanto alcanza a concebir la gente en el exterior de la república mexicana. Por ende, teniendo en cuenta el grado desmesurado de incertidumbre evidenciado en la vivencia nacional -afectada por constantes como la violencia y la pobreza-, imaginarse un futuro dominado por aparatos, en el que la ocasional presencia humana resulte de un desacierto de la ciencia, no es del todo descabellado. En síntesis, estos cuentos, si bien en un principio no destacan por cuanto se acostumbra a identificar como mexicano, son ambos el resultado de un exacerbamiento exploratorio de ciertas características de la realidad nacional -el mito de una gran masa mestiza, el crecimiento agigantado de la demografía, el auge industrial en un país exento de progreso social-, con el fin de plantear críticas mordaces del grado de inequidad imperante en la unión mexicana. Son, en este sentido, una excelente muestra del potencial de la ciencia ficción como herramienta crítica coetánea.

De igual manera, las historias de Haghenbeck y Rojo aprovechan la ciencia ficción para hacerle un ajuste de cuentas a dos omnipresentes constantes mexicanas: el gobierno y los medios de comunicación. Al igual que los previos, éstos también son cuentos que invitan a imaginarse a México de otra forma -sólo que de diferente manera, abordando temáticas y enfoques disímiles-. A veces, ideando circunstancias extremas. En otros casos, haciendo acopio de humor para lidiar con las limitaciones resultantes de un

Ver "Steaming Hot: Mexico's Car industry", del equipo de redacción de The Economist, disponible en: $<$ http://www.economist.com/blogs/schumpeter/2013/11/mexico-s-car-industry>. 
desigual desarrollo económico. En el caso del primer autor, el objetivo es criticar a un Estado que llega muy escasamente a ciertos confines de la geografía nacional y, que en las pocas ocasiones en las que llega, no lo hace precisamente de la manera más amable o desinteresada. En “... Y el ovni cayó (o el evento Ros. Huelitlán)”, Paco Haghenbeck, coautor junto a Óscar Pinto de la afamada serie de historietas Crimson y guionista de Supermán para la DC Comics a fines del 2000, hace acopio de ingenio para burlarse del establishment político y cultural mexicano. La historia nos narra los hechos acontecidos a partir de un sábado 22 de marzo en la localidad de Rosario (por ende, Ros.) Huelitlán en el colorido estado de Oaxaca. A la manera de unas letras castellanas de vieja fecha, la historia comienza con dos campesinos con ejidos contiguos, Rosendo y Melesio, quienes se encuentran en medio de un altercado producto de verdades motivadas por el licor -en un clásico ejemplo de intimidad alcohólica, el primero confiesa haber tenido relaciones con la esposa del segundo-. En ese instante presencian un gran estallido nocturno, resultante del arribo de una accidentada nave espacial, la cual se lleva por delante un tajo de la carretera. (Acto seguido, confiando en fallecer en paz mediante un acto de solidaridad machista, el segundo admite tener relaciones con la esposa del primero). Al ser atendidos por Santiago, el joven médico del pueblo, los dos hombres despiertan sospechas en un par de judiciales, quienes han escuchado de un supuesto siniestro aéreo vinculado al narcotráfico de la zona. El joven galeno nota que los párpados y cejas de sus pacientes están achicharrados, pero, dada la desconfianza que provocan los agentes, se abstiene de comentar. A los pocos días, de manera inesperada, se desata una serie de hechos de naturaleza incierta. Los nuevos equipos de computación de la presidencia municipal se rehúsan a funcionar, circunstancia que Santiago imputa a la naturaleza excéntrica de las máquinas de marca Apple. La nueva plancha de metal de Doña Chema, la tendera del lugar, cocina sin quemar. Las pupilas del hijo de una de sus pacientes adquieren un color fluorescente; el niño acostumbra frecuentar los predios del Rosendo, llenos de fierros viejos. Facundo, un ejidatario cercano, reemplaza su vieja yunta con un nuevo arado que él mismo empuja, como si se tratara de algo liviano. En medio de estos eventos, los judiciales continúan presionando a don Sebastián, el presidente municipal, y tras inquirir en casa del Rosendo, pescan a los supuestos "narcos", a quienes eliminan a punta de tortura, de manera bastante sintomática del México actual, pleno de violencia entre el narco y sus rivales. No obstante, el empecinamiento y embrutecimiento de los judiciales es tal, que confunden a sus verdes prisioneros con rusos. Dentro de esta tónica, los agentes, tan desubicados, quedan un tanto mal parados. Ante el habitual desmán de los judiciales, se da un enfrentamiento, del cual salen mal librados los mismos: la esposa de Rosendo los desintegra con una pistolita de colores extraños, al parecer proveniente del siniestro. Al final del cuento, presenciamos al gobernador de visita, disfrutando de una suculenta barbacoa en compañía de don Sebas, quien se rehúsa a revelar el secreto tras la deleitosa carne de extraño color verde. 
La historia de Haghenbeck lleva la ciencia ficción al México profundo, a la manera de Roswell, Nuevo México - por ende lo de la abreviación a Ros. Huelitlán-, en donde se supone que aconteció un evento de esta índole en junio de 1947. Si en los EE.UU. el supuesto aterrizaje sirvió para generar todo tipo de especulaciones y el consecuente interés turístico, en manos mexicanas, se transforma en una oportunidad de embromar al sistema. En manos de los oaxaqueños, tan idiosincráticos y deslindados del centro del país, la llegada de una nave especial adquiere otros matices. Más que caricaturizarlos, Haghenbeck les aprovecha para postular una jocosa crítica de la brutalidad de un Estado malhechor, empecinado en resolver todo a la fuerza y a punta de cacicazgos. En este sentido, los personajes oaxaqueños de Haghenbeck se prestan para mofarse del establishment azteca y, al tiempo, demostrar la desenvoltura con la que encaran la vida: a la hora de deshacerse de la evidencia de una presencia extraterrestre, ¿qué mejor remedio que cocinar los cuerpos alienígenas y ofrecérselos como atención al gobernador? En otras palabras, la gastronomía nacional, tan representativa de un sentimiento nacionalpopular, aún más allá de cualquier cooptación por parte de la oficialidad, sale al rescate. La respuesta al dilema de los personajes no se encuentra en contemplaciones elaboradas acerca de las implicaciones de su crimen, sino en la naturaleza sencilla y descomplicada del diario vivir campesino. De esa forma, el relato apela a una especie de saber popular, fundamentado en el sentido pragmático de la vida fuera del marco de influencia del Estado y los medios mexicanos. El relato calza a la perfección dentro de una vasta tradición de virtuosismo campechano, remontándose a la era del medievo, en la que, al toparse la modernidad con el mundo ancestral del campo, ésta última se destaca por la sensatez y el desparpajo de sus conclusiones. El México profundo puede que carezca de ciertos aditamentos propios de la vida moderna en las ciudades, pero no por ello deja de ser muy versado en asuntos de la naturaleza humana, aparenta recordarnos este cuento al tiempo que se divierte con la necedades del mismo.

Ahora bien, una de las mayores bondades del relato es cómo postula una auténtica taxonomía del contexto social mexicano. Cada personaje responde según su contexto de clase, radiografiando las debilidades y fortalezas de los mismos. En particular, resulta muy diciente el comportamiento del joven médico residenciado en el poblado, pues la superficialidad y veleidad de sus respuestas -según reza la frase al final del relato, mientras sus necesidades básicas sean satisfechas, poco le atrae el corregir ciertas fallas del presente orden social- delatan la indiferencia de la clase media. De hecho, la motivación inicial para su carrera no es la fortaleza de una vocación hipocrática, sino el anhelo de conquistar gringas bronceadas sirviendo de practicante en Mazatlán. Los otros personajes, desde los dos judiciales al par de campesinos, esgrimen comportamientos esquemáticos, que no por ser estereotipados resultan menos válidos; de ahí el gran contraste entre la esfera gubernamental y una muy espontánea sociedad civil. Ante la ausencia de una presencia estatal -circunstancia sólo reconocida por la clase dirigente mexicana luego de la rebelión zapatista-, la equivalencia entre Oaxaca y Nuevo México 
se da de manera afortunada. Ambas localidades hablan de un asentamiento sumido en lo más profundo de la psique nacional, algo olvidado e ignorado por su dirigencia.

Bien conocido por la longitud de sus cuentos y vinculado a la Facultad de Humanidades de la Universidad Autónoma de Baja California, Pepe Rojo es responsable de nuevas tendencias en el medio cultural mexicano. Entre ellas, cabe destacar el realismo mediático, el cual postula críticas a los medios -tan universales en México-, problematizando la relación de la sociedad con la tecnología y su creciente impacto sobre la realidad nacional. Su cuento "Ruido gris", premiado con el Kalpa en 1996, es posiblemente una de las mejores muestras de los nuevos derroteros de la ciencia ficción mexicana. En ella, el personaje es un joven que, tras recibir dinero de su padre a la edad de los dieciocho años (para luego nunca saber nada más de él), decide operarse y convertirse en reportero ocular. Es decir, mediante una intervención quirúrgica -mitad de la cual es solventada por una compañía con derechos a sus transmisiones-, las terminaciones nerviosas de los ojos y cuerdas vocales del joven son conectadas a un transmisor capaz de difundir una señal audiovisual a canales de video. En suma, según este temerario presagio del cíberpunk azteca, el cuerpo mismo del ser humano se convierte en equipo de grabación, en el que confluyen técnica electrónica y voluntad humana a la merced de los ratings. Para ganarse el pan, el joven habrá de vivir constantemente a la caza de la noticia-suicidios, crímenes, asaltos, toda suerte de hechos mórbidos y truculentos, etc.--, fungiendo de cómplice al amarillismo imperante en los medios de comunicación. He aquí una evolución bastante vernácula del neocentauro de Martínez Sotomayor, menos ocupada en el vértigo del transporte de masas y más centrada en el poder de la imagen. En manos de Rojo, la ciencia ficción mexicana pasa de una economía industrial, fincada en la mecánica del automotor, a una del conocimiento, más acorde con los avances en la tecnología de la información y por lo tanto orientada hacia una cíber-infraestructura ambulante, acarreada por los humanos mismos. Al fin y al cabo, según argumentan los gurúes de la globalización, será la calidad y el nivel de la cíber-infraestructura de las naciones lo que en última instancia habrá de decidir cuáles países ocuparán colocaciones de prominencia en el marco de la economía mundial. Por ende, en un país como México, ceñido al imperio de Televisa y a la fortuna de los Azcárraga -entre quienes destaca de manera obvia Emilio Azcárraga Jean-, tal disquisición acerca de una eventual evolución de los medios hacia una postura aún más nociva jamás queda fuera de lugar.

La perniciosa vocación del espacio televisivo para el cual opera el personaje de la historia-apodado "Rojo Digital" y descrito como el "entretenimiento popular del joven siglo XXI"- queda clara en los matices de su cortinilla de entrada, plena de efectismo. En medio de un frenético desfile de retorcimiento y voyerismo aparecen intromisiones dramáticas en el quirófano, tiroteos desordenados en los que fallece el reportero ocular, tomas de choques desde el punto de vista del conductor, contrapicadas de seres desesperados que se avientan desde las azoteas de edificios, animales sacrificados sin 
escrúpulo alguno en un rastro, asesinatos de políticos, accidentes industriales en los que se pierden extremidades, estallidos en los que el observador sale volando, plagios en los que el secuestrador dispara a la cabeza de un pasajero, etc. En fin, ninguna imagen es suficiente en procura de un mejor rating, buscando llamar más y más la atención de los televidentes. En efecto, al iniciar la historia, acompañamos al protagonista cuando, en un golpe de suerte, buscando concretar imágenes panorámicas de la ciudad, transmite en vivo el suicidio de un pobre diablo, un profesor de gimnasia de cincuenta y cuatro años hastiado del sinsentido de su vida. Acto seguido, le escoltamos a la transmisión de un secuestro fallido, en el que el bebé comprometido es herido por la policía al intentar el rescate. Y aún después, al hallazgo del cuerpo en convulsiones de otro reportero ocular, posible víctima del síndrome de exposición continua a la electricidad (SECLE), enfermedad que pasa a ocupar el puesto del cáncer en el mundo de esta ficción. El personaje continúa emitiendo imágenes y en la prosa se nota el efecto de su ejercicio de periodismo ocular, con una enajenación que va en aumento. Para cuando cruza la raya, contribuyendo al fallecimiento de dos guardas en una tienda departamental y presenciando el estallido de una bomba colocada por terroristas, su deterioro anímico y físico es bastante tangible. Hasta comienza a orinar sangre. Desde este punto de vista, la historia viene revestida de una fuerte connotación psicológica, documentando el desgaste del personaje. En su mundo, la línea divisoria entre la realidad y la televisión parece esfumarse, gracias a la creciente producción y consumo de imágenes. De seguro motivado por la conducta de muchos jóvenes de hoy, acostumbrados a consumir imágenes de forma continua, ya sea desde el televisor o vía Internet, Rojo cuestiona la suerte de una sociedad empecinada en consumir tramas sensacionalistas.

El cuento de Rojo documenta una transición en la sensibilidad de la era moderna, según la cual el cubrimiento noticioso ha devenido en entretenimiento, dejando a un lado su responsabilidad de información. Rojo formula una meditación profunda acerca del papel del comunicador profesional en la sociedad mexicana, sugiriendo su complicidad en una práctica cultural aniquiladora de la individualidad. En medio de un ejercicio que nos hace a todos iguales, quien se sale con la suya es la empresa privada, pese a simular un exceso de la esfera pública. En la prosa de Rojo, el reportero es un factible contribuyente al grado de deterioro informativo de muchas comunidades $-\mathrm{O}$ por lo menos funge de testigo del mismo--, dada la manipulación de la investigación y la imposibilidad de conocer la realidad sin mediación. Teniendo en cuenta la situación del mercado televisivo mexicano, en el que Televisa y TV Azteca se reparten casi la totalidad del mercado - a excepción de los canales Once y Veintidós, y uno que otro canal de cobertura local o regional-, la inquietud de Rojo no es desmedida.

Ahora bien, de forma irónica y a la manera de los cuentos de Schwarz y Trujillo Muñoz, lo de Rojo ha terminado por convertirse en realidad. Hasta cierto punto, anticipa el advenimiento del eyeborg. Rob Spence, un tuerto director de cine residenciado en Toronto, Canadá, ha optado por instalar una cámara en su ojo y transmitir imágenes 
por vía inalámbrica. Su ingenio -o extravagancia, según le juzguen los lectores- ha sido incluso festejado por revistas de la talla de $T I M E{ }^{8}$ Una vez más, la Ciencia ficción mexicana se destaca por su inclinación a pronosticar la vivencia de otros, anticipándose a la realidad. El hecho de que a un mexicano se le ocurra lo que va a hacer un canadiense en cuestión de pocos años nos habla de la capacidad de avance de un socio cultural y comercial impedido por su contexto, producto de la inhabilidad de su clase dirigente. El hecho de que la cuentística mexicana de Ciencia ficción sea tan avezada y acertada en sus predicciones lleva, de manera ineluctable, a pensar acerca de cómo se han digerido, procesado y conjugado los avances tecnológicos derivados del contexto propio y de otras latitudes. En América Latina, la modernidad llegó de manera desordenada y repentina, regida más - con contadas excepciones, como en el caso de González Camarena- por los imperativos de un mercado avasallador que por la dinámica ecuánime de una relación orgánica. Ello tiene sus ventajas y desventajas. A diferencia de otras nacionalidades, no tocó esperar a que se madurara para experimentar una implementación apresurada de tecnología de punta. En algunas partes, se pasó de la incomunicación y el abandono -al estilo de Oaxaca- a la comodidad del celular sin sufrir el via crucis de la telefonía fija, por citar un ejemplo. Si bien buena parte de la población latinoamericana sigue siendo menos móvil que las de otras nacionalidades -gracias a la carencia de alternativas merecedoras en materia de transporte particular y colectivo, y al aún relativamente bajo poder adquisitivo de las juventudes-, ahora resulta mucho más fácil ver cómo se vive y consume en otras partes del mundo, novedad contextual de sueños y aspiraciones de futuras generaciones. Es por ello que conviene prestar atención cuando se escribe del futuro, así venga a cuentagotas: para ver qué se cierne en las mentes de quienes son capaces de imaginarse un mundo diferente, a veces peor, a veces mejor. En un mundo globalizado, en el que las distancias se acortan y el tiempo vuela, la gente tiene menos paciencia con sus jerarquías. En esos instantes, la cultura hace las veces de válvula de escape y ayuda a contemplar lo que se avecina -ése es el terreno de la ciencia ficción-.

\section{BiBLIOGRAFíA}

2001: A Space Odyssey. Stanley Kubrick, dir. Metro-Goldwyn-Mayer, 1968.

Abend, Lisa et al. "The Eyeborg". "The 50 Best Inventions of 2009". TIME. 12 nov. 2009. <http://content.time.com/time/specials/packages/ article/0,28804,1934027_1934003_1933989,00.html>.

Aguirre Beltrán, Gonzalo. Lā población negra de México 1519-1810; estudio etnohistórico. México, DF: Ediciones Fuente Cultural, 1946.

8 La nota de la revista, festejando la ocurrencia de Spence como uno de los mejores inventos de 2009, se encuentra disponible en: <http://content.time.com/time/specials/packages/ article/0,28804,1934027_1934003_1933989,00.html $>$. 
Augustyn, Brian y Humberto Ramos. Crimson. La Jolla: Wildstorm Comics, 1998-2001. Battle Royale. Kinji Fukasaku, dir. AM Associates, 2000.

Bell, Andrea L. y Yolanda Molina-Gavilán, eds. Cosmos Latinos: An Anthology of Science Fiction from Latin America and Spain. Middletown: Wesleyan UP, 2003. 58-60.

Booth, William. The Washington Post. 28 oct. 2012.<http://www.washingtonpost.com/ world/the_americas/mexico-is-now-a-top-producer-of-engineers-but-where-arejobs/2012/10/28/902db93a-1e47-11e2-8817-41b9a7aaabc7_story.html>.

Boulle, Pierre. La planète des synges. París: Livre de Poche, $19 \overline{6} 3$.

Clarke, Arthur C. The Sentinel. Nueva York: Barnes \& Noble, 1996.

Collins, Suzanne. The Hunger Games. Nueva York: Scholastic Press, 2008.

Fernández, Bernardo. Los viajeros: 25 años de ciencia ficción mexicana. México, DF: Ediciones SM, 2010.

González Casanova, Pablo. La literatura perseguida en la crisis de la Colonia. México, DF: El Colegio de México, 1958.

Haghenbeck, F. G.; Gabriel Trujillo Muñoz; Federico Schaffler González y Bernardo Fernández. El evento Ros. Huetlitlán, o, ... Y el ovni cayó. Tijuana, México: UABC, Facultad de Humanidades, 2009.

Harrison, Harry. Make Room! Make Room! Nueva York: Orb, 2008.

Lockhart, Darrell B. Latin American Science Fiction Writers: An A-Z Guide. Westport: Greenwood Publishing Group, 2004.

López Castro, Ramón. Expedición a la ciencia ficción mexicana. México, DF: Editorial Lectórum, 2001.

Martínez Sotomayor, José. Lentitud. México: Imprenta Mundial, 1933.

Mendoza García, María Eulalia y Graciela Tapia Colocia. "Situación demográfica de México 2010”. Fondo de Población de las Naciones Unidas. Disponible en el sitio web del Fondo de Población de las Naciones Unidas: <http://www.unfpa.org.mx/ publicaciones.php>.

"Mexico". Data. The World Bank. <http://data.worldbank.org/country/mexico>.

"Mexico". The World Factbook. CIA. <https://www.cia.gov/library/publications/theworld-factbook/geos/mx.html\#Comm>.

Pacheco, José Emilio. La sangre de Medusa. México, DF: Ediciones Era, 1990.

Planet of the Apes. Franklin J. Shaffner, dir. 20th Century Fox, 1968.

Rojo, Pepe. Ruido gris. México, DF: UAM, 1996.

Schmelz, Itala. "El DF en tono apocalíptico. La literatura mexicana de ciencia ficción y la Ciudad de México". "Dossier thématique : Mexique : espace urbain et résistances artistiques et littéraires face à la "ville générique"”. Artelogie 2. enero 2012. <http:// cral.in2p3.fr/artelogie/spip.php?article89>.

Simak, Clifford D. City. Nueva York: The Gnome Press, 1952.

Soylent Green. Richard Fleischer, dir. Metro-Goldwyn-Mayer, 1973. 
“Steaming Hot: Mexico’s Car Industry". The Economist. 15 nov. 2013. <http://www. economist.com/blogs/schumpeter/2013/11/mexico-s-car-industry $>$.

Takami, Koushun. Battle Royale. Tokyo: Ota Shuppan, 1999.

The Hunger Games. Gary Ross, dir. Lionsgate, 2012.

Trujillo Muñoz, Gabriel. Trujillo Muñoz, Gabriel. Biografías del futuro: la ciencia ficción humana y sus autores. Mexicali: UABC, 2000.

El futuro en llamas: cuentos clásicos de la ciencia ficción mexicana. México, DF: Grupo Editorial Vid, 1997.

Wadhwa, Vivek. "How Mexico Can Leapfrog India and Become America's Automaton Workshop". Forbes. 19 nov. 2012. <http://www.forbes.com/sites/ singularity/2012/11/19/how-mexico-can-leapfrog-india-and-become-americasautomaton-workshop>.

Wall $\bullet$ E. Andrew Stanton, dir. Walt Disney/Pixar, 2008. 
